\title{
Nilai-Nilai Sosial dalam Cerita Film Upin Ipin Tema Pesta Cahaya
}

\author{
Wilda Kholilia' ${ }^{1}$ Imaniar Purbasari², F. Saufika Hilyana ${ }^{3}$ \\ 1,2,3Universitas Muria Kudus, Indonesia \\ E-mail:wkholilia@gmail.com, imaniar.purbasari@umk.ac.id, farah.hilyana@umk.ac.id
}

Article Info
Article History
Received: 2022-02-03
Revised: $2022-02-22$
Published: $2022-03-01$

Published: 2022-03-01

Keywords:

Upin \& Ipin Film;

Social Value;

Elements of Education.

\begin{abstract}
This study aims to describe the educational elements in Upin and Ipin's cartoon films and to analyze the social values contained in Upin and Ipin's cartoons.In this research, the researcher will analyze the knowledge contained in the cartoon film Upin and Ipin as well as the social values in the cartoon Upin and Ipin. The elements of education consist of students, educators, educational interactions between students and educators, educational materials or content (curriculum), contexts that affect education, tools and methods, educators' actions, evaluation and educational goals. In education, several values can be used as a basis for action, one of these values is social values. Social values are the basic values that create and interact with humans between individuals and groups. The approach to this research uses a qualitative approach. The type of research in this research is content analysis. The data techniques in this research are observation and documentation. Data analysis used in this study was data reduction, data presentation, and data levers. the results of the research on social values contained in the film Upin and Ipin Pesta Cahaya are work together, like to help, love, live together, like to give advice and care towards other people.
\end{abstract}

\begin{tabular}{l}
\hline Artikel Info \\
\hline Sejarah Artikel \\
Diterima: 2022-02-03 \\
Direvisi: 2022-02-22 \\
Dipublikasi: 2022-03-01
\end{tabular}

Kata kunci:

Film Upin \& Ipin; Nilai Sosial;

Elemen Pendidikan.

\begin{abstract}
Abstrak
Penelitian ini bertujuan untuk mendeskripsikan unsur pendidikan dalam film kartun Upin dan Ipin dan menganalisis nilai-nilai sosial yang terkandung dalam film kartun Upin dan Ipin. nilai-nilai dalam kartun Upin dan Ipin. Unsur-unsur pendidikan terdiri dari peserta didik, pendidik, interaksi pendidikan antara peserta didik dan pendidik, materi atau isi pendidikan (kurikulum), konteks yang mempengaruhi pendidikan, alat dan metode, tindakan pendidik, evaluasi dan tujuan pendidikan. Dalam pendidikan ada beberapa nilai yang dapat dijadikan sebagai dasar untuk bertindak, salah satunya adalah nilai sosial. Nilai-nilai sosial adalah nilai-nilai dasar yang menciptakan dan berinteraksi dengan manusia antara individu dan kelompok. Pendekatan penelitian ini menggunakan pendekatan kualitatif. Jenis penelitian dalam penelitian ini adalah analisis isi. Teknik data dalam penelitian ini adalah observasi dan dokumentasi. Analisis data yang digunakan dalam penelitian ini adalah reduksi data, penyajian data, dan pengungkit data. Hasil penelitian nilai-nilai sosial yang terkandung dalam film Upin dan Ipin Pesta Cahaya adalah gotong royong, suka menolong, mencintai, hidup bersama, suka menasehati dan peduli terhadap orang lain.
\end{abstract}

\section{PENDAHULUAN}

Pendidikan merupakan suatu hal yang sangat mempengaruhi kemajuan suatu negara, pendidikan yang baik akan menghasilkan penerus bangsa yang berkompeten yang akibatnya nanti akan mewujudkan kemajuan akan suatu negara. Soimin (2014:20) menyatakan Pendidikan merupakan hal yang penting dalam membangun peradaban bangsa, sejalan dengan pendapat Sari (2021) bahwa pendidikan bertujuan agar seseorang mampu berkembang secara optimal dalam setiap prosesnya. Secara umum dikatakan bahwa pendidikan adalah suatu proses yang didesain untuk memindahkan atau menularkan pengetahuan dan keahlian atau kecakapan serta kemampuan (Panjaitan dkk, 2014:22), pada proses pemindahan tersebut tidak hanya mentransfer ilmu pengetahuan tetapi juga transfer of value, yang dapat dilaksanakan di lingkungan sekolah maupun luar sekolah, diera globalisasi seperti ini Pendidikan sangat mudah disalurkan dalam berbagai macam bentuk penyampaian, mulai dari dengan cara permainan, lewat lagu, gambar, video dan lain sebagainya, itu semua merupakan bentuk dari media pembelajaran seperti yang diungkapkan oleh Heinich dalam (Hermawan, dkk 2007:3) media merupakan alat saluran komunikasi. Heinich dalam Hermawan menyatakan bahwa "Media berasal dari bahasa Latin dan merupakan jamak dari kata "medium" yang secara harfiah berarti "perantara" yaitu perantara sumber pesan (a 
source) dengan penerima pesan (a receiver). Heinich mencontohkan media ini seperti film, televisi, diagram, bahan tercetak (printed materials), komputer dan instruktur. Contoh media tersebut bisa dipertimbangkan sebagai media pembelajaran jika membawa pesan-pesan (messages) dalam rangka mencapai tujuan pembelajaran", dimana media sebagai alat komunikasi untuk mentransfer pengetahuan pada anak yang tujuannya untuk mempermudah anak dalam mempelajari pembelajaran atau mengajarkan nilai-nilai Pendidikan kepada anak.

Film kartun Upin Ipin merupakan salah satu bentuk film yang dapat di jadikan sebagai media pembelajaran, dimana serial Upin Ipin dapat di katakana sebagai media audiovisual, audiovisual merupakan gabungan dari kata audio dan visual yang berarti dapat didengar dan diliha, media audiovisual membantu cara berkounikasi menjadi lebih efektif. Media audiovisual merupakan bentuk media pengajaran yang terjangkau, menurut Danesi (2010:134) film dibagi menjadi tiga kategori utama yaitu film fitur, film dokumentasi dan film animasi yang dikenal sebagai film kartun. Pada penelitian ini peneliti memilih media audiovisual berupa film kartun Upin dan Ipin. Film kartun merupakan gambaran dalam bentuk lukisan atau karikatur tentang orang, film kartun sebagai media mempunyai manfaat penting dalam pembelajaran terutama untuk menjelaskan rangkaian isi bahan dalam satu urutan logis mengandung makna, film kartun juga bisa mempercepat daya tangkap anak dalam pembelajaran (Zubaedi, 2011:176).

Alasan peneliti memilih film kartun Upin dan Ipin adalah karena dalam film kartun ini terdiri beberapa tokoh yang berasal dari suku yang berbeda, diantaranya adalah tokoh Mei-Mei yang berasal dari suku China, tokoh Jarjit yang berasal dari suku India, Upin dan Ipin berasal dari suku Melayu, dan tokoh Susanti yang berasal dari Indonesia. Pada penelitian ini peneliti memilih film Upin dan Ipin Musim 13 "Pesta Cahaya", karena pada episode ini mencakup nilai pendidikan yang selaras dengan nilai pendidikan yang ingin dibahas oleh peneliti dalam penelitian ini yaitu nilai sosial. Oleh karena itu, berdasarkan paparan tersebut peneliti mengambil meneliti dan mengambil judul "Analisis Nilai Pendidikan Sosial Yang Terkandung Dalam Film Kartun Upin dan Ipin Musim 13: Pesta Cahaya". Media pembelajaran dalam proses pembelajaran merupakan suatu hal yang sangat penting, karena dengan media pembelajaran seorang anak akan mudah untuk memahami proses pembelajaran yang disampaikan oleh sorang pendidik. Kemajuan ilmu pengetahuan dan teknologi pada saat ini telah bepengaruh terhadap berbagai bidang kehidupan, termasuk dalam dunia Pendidikan, penggunaan alat-alat bantu mengajar disekolah-sekolah dan Lembaga Pendidikan lainnya.

Nilai pendidikan yang akan diteliti dalam penelitian ini adalah nilai sosial berupa bekerja sama, suka menolong, kasih sayang, suka memberi nasehat, peduli terhadap orang lain, dan mendoakan orang lain dalam film kartun Upin dan Ipin Musim 13: Pesta Cahaya. Film kartun dinilai memiliki daya tarik yang tinggi pada anak, karena mempunyai cerita, karakter dan tampilan yang disukai oleh anak, film kartun atau film animasi adalah film yang berasal dari gambar tangan menjadi gambar yang bergera, film merupakan salah satu media yang dapat dimanfaatkan untuk pembelajaran, saat ini penayangan film kartun banyak diputar diberbagai stasiun televisi, salah satu film kartun yang digemari dan kerap ditonton oleh anakanak adalah film Upin dan Ipin produksi Les' Copaque Production, salah satu perusahaan film animasi Malaysia. Di Indonesia film Upin dan Ipin tayang di MNC TV setiap pukul 07.00, 12.00, 16.30, dan 18.00 WIB pada hari Senin-Jumat serta pukul 10.30 dan 12.00 pada hari SabtuMinggu. Film Kartun Upin dan Ipin yang disutradarai oleh Mohd Nizam bin Abd Razak memiliki kisah yang menarik sehingga banyak digemari anak-anak, selain itu serial ini memiliki pesan-pesan yang dapat memberikan pengaruh positif bagi anak. Pada penelitian ini peneliti memilih film kartu Upin dan Ipin, alasan peneliti memilih film kartun Upin dan Ipin adalah karena dalam film kartun ini terdiri beberapa tokoh yang berasal dari suku yang berbeda, diantaranya adalah tokoh Mei-Mei yang berasal dari suku China, tokoh Jarjit yang berasal dari suku India, Upin dan Ipin berasal dari suku Melayu, dan tokoh Susanti yang berasal dari Indonesia (Dahlan, 2015). Pada penelitian ini peneliti memilih film Upin dan Ipin Musim 13 "Pesta Cahaya", karena pada episode ini mencakup nilai pendidikan yang selaras dengan nilai pendidikan yang ingin dibahas oleh peneliti dalam penelitian ini yaitu nilai pendidikan sosial,. Dalam episode Musim 13 "Pesta Cahaya" menceritakan Upin dan Ipin yang membantu Uncle Muthu mempersiapkan perayaan Deepavali. Perayaan Deepavali dalam agama Hindu berarti 'Festival Cahaya', prayaan ini melambangkan kemenangan kebaikan atas keburukan, lampu-lampu dinyala- 
kan dalam perayaan ini sebagai tanda datangnya hari Deepavali serta harapan umat manusia. Perayaan Deepavali berfokus pada lampu dan cahaya, terutama 'diya' tradisional, dalam film Upin dan Ipin Musim 13 "Pesta Cahaya”, Upin dan Ipin membantu Uncle Muthu memperoleh tempat lampu yang telah rusak karena ulah seekor angsa. Hingga pada akhirnya perayaan deepavali tetap bisa terlaksana dengan lancar berkat bantuan Upin, Ipin, Tuk Dalang dan Ah Tong, dalam film ini peneliti akan menganalisis nilai pendidikan berupa nilai sosial yang meliputi bekerja sama, suka menolong, kasih sayang, kerukunan, suka memberi nasehat, peduli terhadap orang lain, dan mendoakan orang lain, serta bagaimana aspek-aspek film tersebut.

\section{METODE PENELITIAN}

Metode yang digunakan dalam penelitian ini adalah pendekatan kualitatif dengan tipe analisis isi. Analisis isi adalah sebuah penelitian terhadap media berdasarkan konteks melalui pemahaman terhadap media yang diteliti (Bungin, 2004:144). Secara umum analisis isi berupaya meng-ungkap berbagai informasi di balik data yang disajikan di media atau teks, analisis isi dapat didefinisikan sebagai teknik mengumpulkan dan menganalisis isi suatu teks atau media yang berupa kata, arti (makna), gambar, simbol, ide, tema, atau beberapa pesan yang dapat dikomunikasikan (Neuman dalam Martono, 2011). Waktu dalam penelitian ini dilaksanakan dalam tiga waktu yang berbeda yaitu tahap perencanaan, tahap pelaksanaan, dan tahap penelitian. Tahap perencanaan dalam penelitian ini dimulai pada Maret 2021, pada tahap pelaksanaan penelitian akan dilaksanakan pada Mei 2021, kemudian pada tahap pelaporan akan dilaksanakan pada Juli 2021. Objek penelitian dalam penelitian ini adalah film kartun Upin dan Ipin Musim 13: Pesta Cahaya, sumber data dalam penelitian ini ada dua yaitu data primer dan juga sekunder, data primer dalam penelitian ini adalah film upin dan ipin sedangan data sekunder dalam penelitian ini adalah jurnal yang terkait dengan penelitian yang dilakukan oleh peneliti. Pengumpulan data dalam penelitian ini ada beberapa diantaranya observasi dan dokumentasi.

\section{HASIL DAN PEMBAHASAN}

Film merupakan bentuk sarana yang dapat dimanfaatkan dalam pembelajaran dengan jenis benda visual serta audiovisual dimana film dapat menjadi media yang sangat menarik banyak minat anak jika dikemas dengan menarik.
Peneliti berusaha meneliti film yang dapat digunakan sebgai media pembelajaran yang dimana dapat menyampaikan pembelajaran serta nilai dalam kehidupan, dalam penelitian ini peneliti memilih film kartun Upin Ipin karena film tersebut merupakan film yang memiliki pesan" moral serta sarana pembelajaran. Berdasarkan pengumpulan dan pengolahan data melalui observasi dan dokumentasi terkait unsur pendidikan dan nilai sosial yang terdapat dalam film Upin dan Ipin Musim 13: Pesta Cahaya, penulis menemukan adanya representasi unsur pendidikan menurut (Sulindawati, 2018:53) dan nilai sosial menurut Alfian (2010) yang berupa bekerja sama, suka menolong, kasih sayang, kerukunan, suka memberi nasehat, peduli terhadap orang lain, dan mendoakan orang lain. Berikut analisis film Upin Ipin yang memiliki pesan-pesan yang mengandung nilai sosial.

1. Bekerjasama

Hasil analisis yang telah peneliti lakukan yang pertama, peneliti menemukan nilai kerja sama yang di sampaikan dalam film kartun Upin Ipin, dalam nilai Kerjasama ini ditunjukkan pada Tokoh dalam adegan tersebut adalah Upin, Ipin, dan Muthu. Latar tempat pada peristiwa tersebut adalah di tepi jalan, dan latar waktu dalam peristiwa tersebut adalah siang hari. Nilai sosial bekerjasama ditunjukkan oleh Upin, Ipin dan Muthu saat ketiga tokoh tersebut membereskan barang-barang yang berserakan di tepi jalan karena roda gerobak yang mereka tumpangi mengalami kerusakan. Dialog dalam adegan tersebut adalah sebagai berikut:

\section{Upin :"Kenape uncle?" \\ Muthu :"Ini roda sudah patah" \\ Ipin : "Lepastu macam mana ni?" \\ Muthu :"Cepat angkat semua barang!"}

Pada tabel kedua di atas adegan terjadi pada menit ke 12:52, tokoh dalam adegan tersebut adalah Upin dan Ipin. Salah satu nilai sosial yang terkandung dalam film Upin dan Ipin adalah bekerjasama, yang merupakan bentuk pengamalan sila ketiga yang berbunyi Persatuan Indonesia. Berdasarkan dialog tersebut peneliti menarik kesimpulan terdapat nilai social yang sampaikan terhadap film Upin Ipin yang menyampaikan nilai sosila berupa aspek Kerjasama hal dimana dalam film tersebut menyampaikan bahwasannya dengan bekerja sama akan cepat menyelesaikan maslah, hal tersebut sesuai dengan pernyataan menurut (Rafian dalam Aisah, 
2015) bahwasannya bekerjasama memiliki memiliki beberapa manfaat, diantaranya adalah pekerjaan menjadi ringan, pekerjaan cepat selesai, dan dapat mempererat persatuan dan kesatuan.

\section{Suka Menolong}

Sebagai makhluk sosial manusia adalah makhluk yang tidak bisa hidup tanpa orang lain, kehidupan manusia akan selalu terhubung dengan manusia lain. Salah satu kebutuhan dasar manusia sebagai makhluk sosial adalah suka menolong atau tolong menolong Rahman (dalam Putra dan Rustika, 2015: 200), nilai sosial suka menolong pada adegan tersebut ditunjukkan oleh tokoh Upin yang membantu membereskan barang milik tokoh Muthu yang berserakan di tepi jalan karena gerobak yang ditumpanginya mengalami kerusakan pada roda, tindakan yang dilakukan oleh Upin dan Ipin adalah perilaku yang terpuji. Tindakan yang dilakukan oleh Upin dan Ipin yang berusaha menolong paman Muthu sesuai dengan pernyataan (Duski, 2015:9) tentang pengertian sikap suka menolong, yaitu suka menolong adalah sikap dan tindakan yang selalu berusahan membantu orang lain. Membantu orang lain memberikan banyak manfaat, baik untuk penolong atau orang yang ditolong. Membantu orang lain dapat mempererat tali persaudaraan, menjadikan pekerjaan cepat selesai, dan pekerjaan terasa lebih ringan. Contoh implementasi sikap tolong menolong sangat dianjurkan ketika bekerja kelompok di sekolah, akan tetapi penerapan sikap tolong menolong tidak dianjurkan pada pelaksanaan ulangan di sekolah. Dialog pada cuplikan film tersebut yang mengambarkan sikap tolong menolong adalah sebagai berikut:

\section{Upin :"Kenape uncle?" \\ Muthu :"Ini roda sudah patah" \\ Ipin : "Lepastu macam mana ni?" \\ Muthu :"Cepat angkat semua barang!"}

Nilai sosial yang ditunjukkan pada tabel kedua terdapat pada menit ke 12:52, berdasarkan percakapan diatas terdapat aspek nilai social yang disampaikan dalam kartun Upin Ipin yaitu tolong menolong, dimana upin dan Ipin menolong paman Mutho yang roda gerobaknya sedang rusak. Dari bagian film diatas peneliti menyimpulkan bahwasannya film Upin Ipin tersebut mengandung pesan untuk dismpaikan kepada penonton untuk tolong menolong sesama baik dengan tenaga, materi ataupun jasa hal tersebut sesuai dengan pendapat Maikomah dkk, (2018:206) bahwasannya seseorang yang hidup di lingkungan masyarakat wajib melakukan kegiatan tolong menolong, bentuk dari tolong menolong dapat berupa materi, tenaga, dan moral dan Kegiatan tolong menolong yang dilakukan oleh Upin dan Ipin merupakan kegiatan tolong menolong yang berupa tenaga sesuai dengan pernyataan.

\section{Kasih Sayang}

Nilai sosial kasih sayang tidak hanya tertuju pada pasangan, nilai sosial kasih sayang dapat ditujukan kepada orang tua, saudara, teman, lingkungan dan benda-benda yang dimiliki (Burhani dalam Aisyah, 2016). Nilai sosial kasih sayang juga terkandung dalam film Upin dan Ipin, nilai sosial kasih sayang terdapat pada adegan film menit ke 01:04. Latar tempat pada adegan di atas adalah di teras rumah tokoh Muthu, sedangkan latar waktu dalam cuplikan film tersebut menunjukkan pagi hari berdasarkan dialog tokoh Muthu berupa:

\section{Muthu :"Ayoyo budak kecil dah bangun"}

Nilai sosial kasih sayang berhubungan dengan sikap yang menunjukkan perasaan penuh kasih sayang dan sikap penuh kelembutan sehingga ada keterjalinan rasa saling melindungi (Widianti dkk, 2017:30). Nilai sosial kasih sayang yang dimaksud oleh (Widianti dkk, 2017:30) ditunjukkan pada adegan Muthu memijat kepala, rambut, dan pundak tokoh Rajoo, meskipun dalam adegan tersebut tidak terdapat dialog yang menyebutkan nilai sosial kasih sayang secara langsung, tetapi adegan yang ditayangkan menunjukkan nilai sosial kasih sayang. Nilai sosial kasih sayang tersebut tergambar dalam adegan di mana tokoh Muthu menggendong Rajoo kemudian memijat kepala, rambut dan anggota tubuh lain milik tokoh Rajoo dengan penuh kelembutkan dan ketulusan sehingga memancarkan perasaan bahagia sekaligus haru pada ekspresi paman Muthu dalam adegan tersebut. Pada adegan tersebut tergambar hubungan kasih sayang yang erat antara orang tua dan anak, dalam keluarga nilai sosial kasih sayang tidak hanya digambarkan melalui orang tua dan anak, nilai sosial kasih sayang juga dapat digambarkan melalui hubungan antar saudara, ketulusan yang digambarkan oleh paman Muthu terhadap Rajoo selaras dengan pendapat 
Rahmatullah (2014: 35) mengenai unsurunsur kasih sayang yang salah satu diantaranya adalah adanya unsur kedekatan emosional dan tidak adanya unsur kekerasan, penghinaan, umpatan, pemaksaan dan pukulan, unsur tersebut tergambar dalam perlakuan yang ditunjukkan paman Muthu kepada Rajoo dalam cuplikan film di atas.

Untuk mengupas lebih mendalam mengenai film Upin dan Ipin Pesta Cahaya, pada penelitian ini peneliti melakukan analisis sinematografi pada cuplikan film yang menunjukkan nilai sosial kasih sayang dalam film tersebut. Sinematografi pada tabel pertama, teknik pengambilan gambar adegan tersebut menggunakan teknik long shot, pada cuplikan film tersebut, penonton dapat melihat dengan jelas kegiatan yang dilakukan oleh paman Muthu dan Rajoo beserta kondisi sekitar teras rumah paman Muthu.

\section{Kerukunan}

Kerukunan dapat diciptakan di mana saja, baik dalam lingkungan keluarga, masyarakat, dan lingkungan sekolah, kerukunan akan menciptakan ketenangan dalam hidup dan terhindardari pertikaian. Jika seseorang sudah terbiasa hidup rukun dalam lingkungan keluarga, maka orang tersebut dapat menjalankan kerukunan dalam lingkungan masyarakat (Ribka dalam Aisah, 2015). Berdasarkan tabel diatas, terdapat dua nilai sosial kerukunan yang ditemukan dalam film Upin dan Ipin pesta Cahaya. Kerukunan dalam film tersebut tercipta karena adanya toleransi yang digambarkan dalam film, menggambarkan nilai sosial kerukunan tersebut adalah sebagai berikut:

$\begin{array}{ll}\text { Upin } & \text { :"Pandai kau orang buat. } \\ & \text { Wahh" } \\ \text { Mei-Mei } & \text { :Devi ajar ma" } \\ \text { Upin dan Ipin } & \text { :Hebatlah Devi" } \\ \text { Upin } & \text { :"Ajarlah kita orang" } \\ \text { Devi } & \text { :Buat sendiri lah, nah } \\ & \text { cuba" } \\ \text { Upin dkk } & \begin{array}{l}\text { :"Yeay siap" } \\ \text { Upin } \\ \text { :Ini namanye kolam } \\ \text { kawan-kawan" }\end{array}\end{array}$

Nilai sosial kerukunan dalam film Upin dan Ipin Pesta Cahaya ditunjukkan pada menit ke 06:45, nilai sosial hidup bersama dalam film tersebut tergambar pada adegan Upin, Ipin, Devi, Mei-Mei dan Susanti bersama-sama membuat gambar warna yang berasal dari beras tanpa memandang latar belakang ras dan suku satu sama lain. Perbedaan antara bahasa dan logat bahasa pun tidak mempengaruhi pertemanan dan kerukunan yang digambarkan dalam film, mereka tetap dapat saling memahami, menghormati, dan bermain bersama-sama. Dari dialog diatas nilai social yang di sampaikan dalam film tersebut yaitu nilai social kerukunan, dimana nila kerukunan tersebut disampaikan dalam film Ketika adegan sedang ada terjadi sebuah percakapan yang menunjukkan sikap saling menghargai atas karya orang lain dan terjalin sikap rukun dan saling toleransi antar etnis. Hal tersebut sama dengan pendapat Ansori, (2010:152) yang menyatakan bahwa Toleransi adalah sikap dan tindakan yang menghargai perbedaan agama, suku, etnis, pendapat, sikap, dan tindakan orang lain yang berbeda dari dirinya.

5. Suka Memberi Nasehat

Kehidupan dimasyarakat tentunya sangat menyenangkan, bertemu dengan banyak karakter yang berbeda-beda tentunya banyak menimbulkan hal yang baru. Tentunya dalam kehidupan masyarakat kita menemukan ada sisi kehudpan yang baik dan yang buruk, nah Ketika kita menumakan suatu hal yang baik maka baiknya kita meniru dan Ketika kita menemukan hal yang kurang baik dari masyarakat baiknya kita memberikan nasehat atau menegur dengan cara yang halus. Salah satu nilai sosial menurut Alfiah (2010) adalah memberi nasehat. Nasehat adalah ajaran atau pelajaran baik, anjuran (petunjuk, peringatan, teguran) yang baik, memberi nasehat berarti memberikan ajaran atau petunjuk yang baik kepada orang lain. Selain menerima nasihat dari orang lain, menasehati orang lain pun tidak ada salahnya karena secara tidak langsung akan memberikan solusi dan kebaikan yang terdapat dalam diri akan tersalurkan, nasihat yang diberikan pun harus masuk akal dan selaras supaya dapat memperbaiki kesalahan yang dilakukan oleh orang yang menerima nasehat tersebut (Abdilah dalam Ekasari, 2018:9).

Nilai sosial sering kali dijumpai dalam sebuah film, salah satunya adalah film Upin dan Ipin, dalam film ini ditemukan nilai sosial memberi nasehat pada menit ke 07:20, film tersebut menunjukkan adegan di mana Upin dan Ipin sedang bermain bola di jalan depan Kedai Runcit. Opah yang pada saat itu keluar dari Kedai Runcit langsung memberi nasehat kepada Upin dan Ipin agar tidak bermain di 
jalan, latar tempat dan latar waktu pada adegan tersebut adalah di depan Kedai Runcit pada siang hari, dialog pada adegan tersebut adalah sebagai berikut:

$\begin{array}{ll}\text { Upin } & \text { :Nah Upin, sambung." } \\ \text { Opah } & \text { :Eii jangan main di tengah } \\ & \text { jalan, bahaye." } \\ \text { Upin dan Ipin } & \text { :"Ee hehe baik Opah" }\end{array}$

Dari percakapan yang di utarakan oleh tokoh Upin Ipin diatas, mengandung nilai social yaitu memberi nasehat yang disampaikan oleh opah yang tujuannya untuk kebaikan dimana ipin dan upin dilarang bermain unutk tidak bermain di jalan, dari dialog tersebutt dapat dilihat nilai social sama yang diungkapkan oleh Abdilah dalam (Ekasari 2018:9) yang mengungkapkan bahwasannya jika seorang menasehati kepada orang lain yang sedang salah ataupun keliru hal tersebut ditujukan untuk kebaikan dari orang tersebut untuk menuju kebaikan.

\section{Peduli Terhadap Orang Lain}

Manusia merupakan makhluk sosial yang tidak bisa hidup tanpa adanya orang lain, dalam kehidupan ini tentunya membutuhkan orang lain untuk berlangsungnya kehidupan seorang individu artinya setiap manusia tidak bisa hidup tanpa manusia yang lain. Peduli adalah sikap keberpihakan kita untuk melibatkan diri dalam persoalan, keadaan atau kondisi yang terjadi di sekitar kita, orang yang peduli terhadap orang lain adalah mereka yang selalu memberikan kebaikan kepada orang-orang disekitarnya (Arifin, 2001:54). Pendapat yang dikemukakan Arifin selaras dengan nilai sosial peduli terhadap orang lain yang terdapat dalam film Upin dan Ipin Pesta Cahaya, berdasarkan penelitian peneliti, terdapat dua cuplikan film yang menunjukkan nilai sosial peduli terhadap orang lain. Pada tabel pertama nilai sosial peduli orang lain ditunjukkan pada menit ke 04:59 dalam film, adegan tersebut menunjukkan Upin dan Ipin yang mengkhawatirkan keadaan Mei-Mei dan menanyakan kondisi Mei-Mei setelah diganggu oleh Rembo. Tokoh dalam cuplikan film tersebut adalah Upin dan Ipin, latar tempat dan waktu pada cuplikan film tersebut adalah di Pondok bermain pada siang hari. Dialog pada cuplikan film tersebut adalah sebagai berikut:

$$
\begin{array}{ll}
\text { Susanti } & : \text { "Hayoyo" } \\
\text { Mei-Mei } & \text { :Hayah" } \\
\text { Mei-Mei } & \text { :Kejar dia!" }
\end{array}
$$

$\begin{array}{ll}\text { Upin } & : \text { "Jom" } \\ \text { Upin } & : \text { "Kenape Me-Mei?" } \\ \text { Mei-Mei } & \text { :"Tenggok!" } \\ \text { Mei-Mei } & \text { :"Rembo kacau kita orang buat } \\ & \text { kolam" }\end{array}$

Perilaku Upin mencerminkan kepedulian sosial kepada teman, tindakan Upin dalam film menunjukkan salah satu nilai karakter yang dikemukakan oleh (Anone Juanda dalam Rumyeni, 2016:6) berupa nilai peduli sosial. Nilai peduli sosial adalah tindakan yang selalu ingin memberi bantuan kepada orang lain yang membutuhkan, dalam cuplikan film tersebut, setelah menanyakan kondidi Meimei, Upin membantu Mei-mei dan temantemannya menangkap Rembo bersama Ipin supaya tidak menggangu Mei-mei dan temantemannya bermain. Dalam penggalan cerita upin-ipin tersebut ditarik kesimpulan oleh peneliti bahwasannya dalam adegan tersebut ada nilai social yang ditampilkan berupa peduli terhadap orang lain dimana Upin, Ipin dankawan-kawan membantu mei-mei untuk mengusir rembo yang sedang mengganggu mei-mei yang sedang membuat kolam hal tersebut sejalan dengan pendapat oleh Arifin (2001:54) bahwasannya orang yang perduli terhadap lingkungan ataupun orang sekitar adalah orang yang bermanfaat bagi sekitarnya.

\section{SIMPULAN DAN SARAN}

\section{A. Simpulan}

Nilai sosial yang terkandung dalam film Upin dan Ipin Pesta Cahaya adalah bekerja sama, suka menolong, kasih sayang, hidup bersama, suka memberi nasehat dan peduli terhadap orang lain. Nilai sosial bekerja sama berupa bentuk kerja sama untuk membereskan barang-barang paman Muthu yang berserakan di tepi jalan dan bentuk kerja sama menyelesaikan gambar warna milik paman Muthu. Nilai sosial suka menolong dalam film terdapat pada adegan saat tokoh Upin membantu paman Muthu membereskan barangnya yang berserakan di tepi jalan dan saat Upin membantu menyelesaikan gambar warna milik Muthu, nilai sosial kasih sayang dalm film ditunjukkan pada adegan paman Muthu mengusapkan minyak pada kepala dan anggota tubuh lain Rajoo, nilai sosial kerukunan yang terdapat dalam film terdapat dalam adegan saat Upin dan Ipin bermain bersama teman-temannya tanpa membedakan ras, agama, dan bahasa, serta para 
pemeran dalam tokoh Upin dan Ipin yang nampak bahagian dalam menghadiri perayan deepavali yang diselenggarakan oleh paman Muthu, nilai sosial suka memberi nasehat terlihat pada adegan Opah menasehati Upin dan Ipin untuk tidak bermain di lapangan dan untuk bersikap baik pada paman Muthu saat pulang bersama, nilai sosial yang terakhir berupa sikap peduli terhadap orang lain terdapat pada adegan Upin yang menghampiri Mei-mei dan menanyakan perihal kondisi Meimei, dan pada adegan paman Muthu menawarkan tumpangan kepada Opah untuk pulang bersama.

\section{B. Saran}

Adapun saran yang dapat disampaikan untuk peneliti selanjutnya untuk dapat mengembangkan bukan hanya dari 1 studi film.

\section{DAFTAR RUJUKAN}

Abu Ahmadi dan Nur Uhbiyati. 2001. Ilmu Pendidikan. Jakarta: PT Rineka Cipta.

Afro, A. S., \& Anwari, M. R. (2020, September). Nilai-Nilai Moral dalam Film Keluarga Cemara dan Implementasinya Sebagai Materi Pembelajaran Sastra di SMP. In Urban Green Conference Proceeding Library (Vol. 1, pp. 106-111).

Ahmad, J. (2018). Desain penelitian analisis isi (Content analysis). Research Gate, 5(9).

Ameliola, S., \& Nugraha, H. D. (2013, June). Perkembangan media informasi dan teknologi terhadap anak dalam era globalisasi. In Prosiding In International Conference On Indonesian Studies" Ethnicity And Globalization.

Andriana Ridho, M. (2019). Nilai-Nilai Pendidikan Karakter Peduli Sosial dalam Film Animasi Upin dan Ipin (Musim Sembilan Tajuk Kedai Makan Upin dan Ipin). QALAMUNA: Jurnal Pendidikan, Sosial, dan Agama, 11(2), 173-182.

Anggia, S., \& Mahyuddin, N. (2020). PENGARUH PENGGUNAAN MEDIA FILM ANIMASI UPIN DAN IPIN TERHADAP PERILAKU SOSIAL ANAK DI TAMAN KANAK-KANAK AISYIYAH PADANG PANJANG. Jurnal Pendidikan Tambusai, 4(1), 428-433.
Astuti, R. D. (2016). Nilai Sosial dalam Novel Gadis Pantai Karya Pramoedya Anantatoer. Jurnal Pesona, 2(1).

Candra Ekasari, N. (2018). Nilai Sosial Kumpulan Cerpen The Story of Keresidenan Besuki (Doctoral dissertation, Universitas Muhammadiyah Jember).

Candra Ekasari, N. (2018). NILAI SOSIAL KUMPULAN CERPEN THE STORY OF KERESIDENAN BESUKI (Doctoral dissertation, Universitas Muhammadiyah Jember).

Danesi, Marcel. 2010. Pengantar Memahami Semiotika Media. Yogyakarta: Jalasutra.

Dolong, J. (2016). Teknik analisis dalam komponen pembelajaran. Jurnal Inspiratif Pendidikan, 5(2), 293-300.

Duski, A. (2015). Nilai-Nilai Karakter Bangsa pada Buku Kumpulan Dongeng Fabel Karya

Hasbullah. 2005. Dasar-Dasar Ilmu Pendidikan. Jakarta: PT Grafindo Jaya.

Hermawan, Asep Henry dkk. Media Pembelajaran Sekolah Dasar. 2007. Bandung: UPI PRESS.

Maikomah, S., Zahar, E., \& Masni, H. (2018). Analisis Nilai Etika Tolong-Menolong Tokoh Hepi Dalam Novel Anak Rantau Karya A. Fuadi. Jurnal Ilmiah Dikdaya, 8(1), 204-212. Karakteristik Anak Usia Dini.

Martono, Nanang. 2011. Metode Penelitian Kuantitatif: Analisis Isi dan Analisis Data Sekunder. Jakarta: Raja Grafindo Persada.

Panjaitan, Ade Putra dkk. Korelasi Kebudayaan\&Pendidikan Membangun Pendidikan Berbasis Budaya Lokal. 2014. Jakarta: Yayasan Pustaka Obor Indonesia.

Purnama, M. N. A. (2020). NILAI-NILAI PENDIDIKAN MORAL (SANTUN DAN HORMAT PADA ORANG LAIN) DALAM FILM ANIMASI NUSSA DAN RARA (DALAM EPISODE KAK NUSSA).SCAFFOLDING: Jurnal Pendidikan Islam dan Multikulturalisme, 2(1), 38-48.

Rachman, M. (2013, June). Pengembangan pendidikan karakter berwawasan konservasi nilai-nilai sosial. In Forum ilmu sosial (Vol. 40, No. 1). 
Rahmah, S. (2019). Pola komunikasi keluarga dalam pembentukan kepribadian anak. Alhadharah: Jurnal Ilmu Dakwah, 17(33), 13-31.

Republik Indonesia, Undang-undang Republik Indonesia No 14 Tahun 2005 tentang Guru dan Dosen \& Undang-undang Republik Indonesia No 20 Tahun 2003 tentang sisdiknas, (Bandung: Permana, 2006).

Rumyeni, R., \& Anwar, R. (2016). Pengaruh Film Animasi Upin Dan Ipin Terhadap Penerapan Nilai Sosial Siswa Di Sdn 006 Sekolubuk Tigo Lirik (Doctoral dissertation, Riau University).

Rusman Latief \& Yusiaties Utud. Siaran Televisi Non-drama. 2017. Jakarta:Kencana.

Sari, W. N. 2021. Pendidikan Karakter Melalui Pembelajaran IPS. PESHUM : Jurnal Pendidikan, Sosial Dan Humaniora, 1(1), 10-14. Retrieved from https://ulilalbabinstitute.com/index.php/P ESHUM/article/view/6

Shoimin, Aris. 2014.68 Model Pembelajaran Inovatif dalam Kurikulum 2013. Yogyakarta: Ar-Ruzz Media.
Sitompul, E. A., \& Simaremare, J. A. (2017). Analisis Fungsi, Nilai Budaya dan Kearifan Lokal dalam Film Sinamot Karya Sineas Muda Medan: Kajian Antropolinguistik. Suluh Pendidikan, 4(2), 24-37.

Susanti, A., \& Asyari, I. (2017). Nilai Pendidikan dalam Film Alangkah Lucunya Negeri Ini. MEDIAKOM, 1(1).

Syafnedi, D., \& Aminudin, A. (2020). Representasi Nilai Pendidikan Pada Film Iqro: My Universe. PANTAREI, 4(03).

Wati, D. C., \& Arif, D. B. (2017). Penanaman nilainilai religius di sekolah dasar untuk penguatan jiwa profetik siswa.

Widodo, A. (2020). Nilai budaya ritual perang topat sebagai sumber pembelajaran IPS berbasis kearifan lokal di sekolah dasar. Gulawentah: Jurnal Studi Sosial, 5(1), 1. 